\title{
A review of interoperability standards in e-Health and impera- tives for their adoption in Africa
}

\author{
Funmi Adebesin*†, Rosemary Foster ${ }^{\dagger \ddagger}$, Paula Kotzé*†, Darelle van Greunen ${ }^{\dagger}$ \\ * CSIR Meraka Institute, South Africa \\ $\dagger$ School of ICT, Nelson Mandela Metropolitan University, South Africa \\ $¥$ Medical Research Council, South Africa
}

\begin{abstract}
The ability of healthcare information systems to share and exchange information (interoperate) is essential to facilitate the quality and effectiveness of healthcare services. Although standardization is considered key to addressing the fragmentation currently challenging the healthcare environment, e-health standardization can be difficult for many reasons, one of which is making sense of the e-health interoperability standards landscape. Specifically aimed at the African health informatics community, this paper aims to provide an overview of e-health interoperability and the significance of standardization in its achievement. We conducted a literature study of e-health standards, their development, and the degree of participation by African countries in the process. We also provide a review of a selection of prominent e-health interoperability standards that have been widely adopted especially by developed countries, look at some of the factors that affect their adoption in Africa, and provide an overview of ongoing global initiatives to address the identified barriers. Although the paper is specifically aimed at the African community, its findings would be equally applicable to many other developing countries.
\end{abstract}

KEYWORDS: E-health, interoperability, standards, standards development organizations.

CATEGORIES: J.3, K.4.1

\section{INTRODUCTION}

The healthcare domain is highly transaction-intensive and requires interactions between the multidisciplinary team of healthcare professionals, the subject of care or patient, administration personnel, medical insurers, suppliers and other stakeholders [1] 2] 3]. Quality healthcare requires effective collaboration and the ability to communicate essential information between and among all the stakeholders in order to facilitate continuity of care 4 .

The adoption of information and communication technologies (ICT) to support healthcare delivery has the potential to positively impact the quality of care, improve healthcare service efficiencies, and enable scaleup of healthcare programmes especially in hard-toreach communities in developing countries [5] 6]. According to World Health Organization (WHO) and International Telecommunication Union (ITU) [7, this is simply what e-health entails, i.e., the use of ICTs

Extended paper, originally published as "Barriers and Challenges to the Adoption of E-Health Standards in Africa", Health Informatics South Africa (HISA) 2013 Conference, 3 - 5 July 2013.

Email: Funmi Adebesin fadebesin@csir.co.za, Rosemary Foster foster.ehealth@gmail.com, Paula Kotzé paula.kotze@meraka.org.za, Darelle van Greunen Darelle.vanGreunen@nmmu.ac.za for health.

E-health offers many benefits to healthcare consumers, providers, as well as managers and policy makers. From a consumer's perspective, e-health facilitates access to quality healthcare services, especially to people in remote and under-resourced communities. Consumers can receive better and safer healthcare, since relevant health information is more readily available to care providers when required. Consumers also become active participants in ensuring their well-being through access to more reliable, accredited health information 8.

For the provider, e-health supports informed decision making through the availability of more accurate health information, access to medical knowledge databases and best practises. Multidisciplinary teams of care providers can share health information and coordinate health interventions in an effective manner, thereby reducing unnecessary duplication of efforts. Adverse drug events can be averted through the use of e-prescription systems that flag alerts when an order is made for medications which have adverse interactions with other medications that a patient is currently on, or to which the patient is known to be allergic. Furthermore, time spent clarifying and re-writing illegible prescriptions is freed up and can be better utilized [8].

Policy makers benefit from e-health through access to more accurate and reliable information, upon which healthcare investment decisions can be based. Thus, 
health service interventions can be directed to where they are most urgently needed. Managers can better monitor and evaluate health intervention programmes through access to more accurate national health data summaries [8].

Despite the potential of e-health to positively influence the quality of care and improve healthcare service efficiencies, its widespread adoption has been very slow due to a number of factors, including the high cost of acquisition, especially at the initial stage 9, resistance to change on the part of healthcare professionals [10, security, privacy and confidentiality concern [9] [11, and lack of technical skills [9]. The inability of healthcare information systems (HISs) to interoperate on a national scale exacerbates the slow uptake of ehealth. According to the ITU [12, one of the barriers to reaping the full benefits of e-health is this inability to share information.

Standardization is key to achieving interoperability. However, the e-health standardization arena is fraught with many challenges, which include the huge number of available standards, with many of them competing and overlapping, and some even contradicting one another [13] [14.

This paper provides a literature review of what interoperability entails in the healthcare domain and the special role of standardization in the achievement of interoperability. Currently, e-health interoperability and standardization, as well as their level of adoption in Africa, is under-researched, with little or no published research available. The paper primarily aims to inform the health informatics community in Africa, who may be looking for an overview of, or introduction to, the ehealth interoperability and standardization landscape.

The remainder of the paper is structured as follows: in Section 2, we give an in-depth discussion of e-health interoperability, its levels, benefits and challenges, as well as the factors that enable interoperability. Section 3 provides a summary of e-health standards development landscape through a review of the prominent standards development organizations (SDOs). Section 4 takes a look at the role of standardization in achieving interoperability. In addition to providing the benefits of standardization, the section includes a classification scheme for e-health interoperability standards, together with the level(s) of interoperability that are typically addressed by such standards (using a selection of standards as examples). Section 5 gives an overview of e-health standards adoption and implementation in Africa, highlights the prevalence of non-interoperable healthcare systems on the continent and some of the challenges that prevent the widespread adoption of e-health interoperability standards. In Section 6, we discuss some of the global initiatives to overcome the barriers. We conclude the paper in Section 7 .

\section{E-HEALTH INTEROPERABILITY}

Broadly speaking, interoperability is the ability of two or more systems or components and the business processes they support to exchange information and use the information that has been exchanged [15]. More specifically, within the healthcare domain, interoperability is defined as "the ability of health information systems to work together within and across organizational boundaries in order to advance the health status of, and the effective delivery of healthcare for individuals and communities" [16].

\subsection{Levels of e-health interoperability}

Currently, there is no consensus on the levels of interoperability. While some authors have defined three levels [16] 17, others have identified up to seven levels [18. For the purpose of this paper, we use the four levels of interoperability as defined by Whitman and Panetto [19] and the European Telecommunication Standards Institute [20], namely technical, syntactic, semantic and organizational (Fig. 1).

Technical interoperability enables heterogeneous systems to exchange data, but it does not guarantee that the receiving system with be able to use the exchanged data in a meaningful way [19] 20]. Syntactic interoperability guarantees the preservation of the clinical purpose of the data during transmission among healthcare systems, while semantic interoperability enables multiple systems to interpret the information that has been exchanged in a similar way through pre-defined shared meaning of concepts. The highest level of interoperability, organizational interoperability, facilitates the integration of business processes and workflows beyond the boundaries of a single organization [19] 20]. In addition to the presence of the three lower levels of interoperability, organizational interoperability requires strong willingness and commitment from the concerned organizations to collaborate [19].

\subsection{Benefits of e-health interoperability}

The importance of interoperable e-health systems in strengthening modern-day healthcare system is indisputable. The realization of the full benefits of e-health investments is reduced without the ability of HISs to share information among each other.

Interoperability enables timely access to patient information whenever and wherever needed. It also reduces the need to re-capture the same information in every system and the accompanying data capture errors that could arise from the entry of the same information multiple times [21] [22].

Timely access to patient information at the point of care empowers healthcare professionals, since they are able to make informed decisions and provide personalized care to patients based on more accurate information. This is in addition to the improvement in patient safety that could accrue from the use of interoperable electronic prescription systems and clinical decision support systems, which reduce the incidence of medical errors 23. It is reported that medical errors cause more deaths in the United States than breast cancer or acquired immunodeficiency syndrome (AIDS) 24. Interoperability also enables better healthcare coordination to support continuity of care through the 


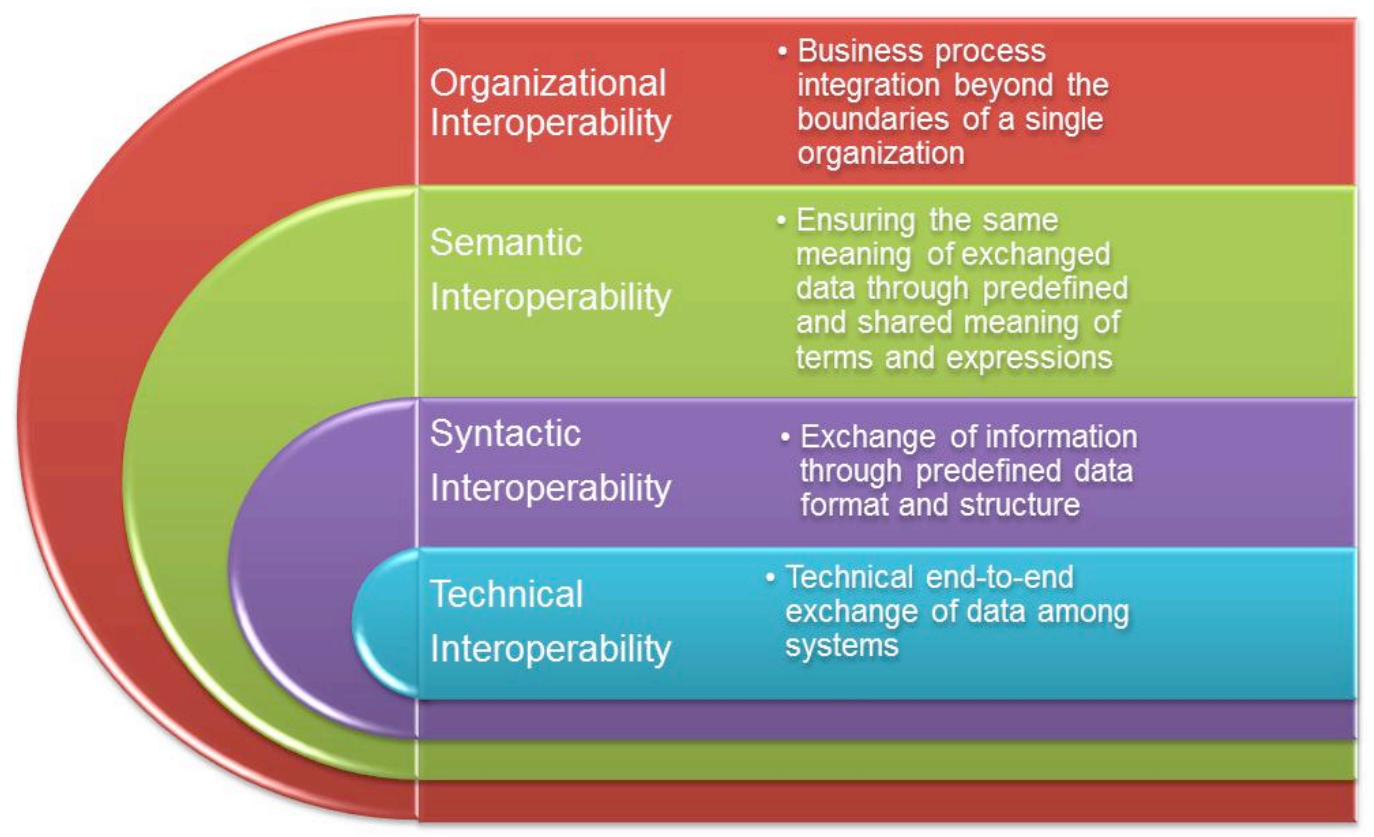

Figure 1: Levels of interoperability (adapted from [20])

improved communication of referral notes, patients' medical history, laboratory test results and other relevant documents in a structured manner [25] [26].

\subsection{Why e-health interoperability is difficult}

Although several global health and e-health stakeholders have continued to emphasize the important role of interoperability in leveraging ICT to improve healthcare delivery, achieving interoperability of healthcare systems remains a daunting challenge. For example, at the recent sitting of the 66th World Health Assembly [27, the current fragmentation of HISs was acknowledged as an obstacle to realizing the full benefits of e-health. The question that then arises is, why is e-health interoperability so hard to attain? This section provides an overview of some of the challenges to e-health interoperability.

The healthcare domain is highly complex. Part of this complexity has to do with the human body itself, which does not lend itself to a complete understanding by a single individual. This has led to the creation of specialties and sub-specialties in the healthcare profession. In addition, the healthcare sector typically deals with large data sets in various formats, such as, numerical measurements, free text narratives, structured text, multimedia diagnostic images, as well as clinical and financial codes [2] 3] 8]. Achieving interoperability, especially at semantic level, is more difficult in healthcare when compared with, for example, the banking sector. A major contributor to this is the ambiguity that may arise from the use of medical terms.

Overcoming major differences in organizational cultures, behaviours and business processes is another hurdle, especially when the goal is to attain organizational interoperability. As stated in Subsection 2.1. high level of commitment to align business processes is essential to achieve organizational interoperability, and all stakeholders need to be motivated to move beyond their 'ways of doing things' to a shared/common way [19] 28] 29].

Another challenge to e-health interoperability relates to the myriad of legacy systems that are currently in place. Many of these systems are based on different data formats and structure, incompatible operating systems, application servers, and databases. Due to the substantial investment that has been made in the implementation of these legacy systems, many healthcare organizations may be reluctant to spend more money on interoperable solutions [28, 29].

The widespread adoption of interoperable e-health solutions is also being constrained by genuine concern for privacy, security and confidentiality of personal health data. Seamless exchange of healthcare information requires a commitment from relevant stakeholders, assuring patients that their personal health data will be secured and protected from unauthorized access. As such, stringent privacy and confidentiality protection through the promulgation and enforcement of appropriate law is a pre-requisite to e-health interoperability 30. 31.

\subsection{Drivers of e-health interoperability}

As discussed in Subsections 2.2 and 2.3, interoperability is important but difficult to attain in the healthcare domain. In their e-health Strategy Toolkit [7], the WHO and ITU identified seven components that should be part of any country's e-health plans and initiatives (Fig. 2). Five of the components are classified as enabling environments and the remaining two are the necessary physical infrastructure or ICT environments.

Interoperability specifications should form an integral part of any successful e-health initiative, since positive return on investment is highly dependent on the availability of health information whenever and 
wherever it is required to support continuity of care. Because interoperability cannot be separated from the wider e-health discussion, we applied the WHO and ITU components in the illustration of factors that are essential to effectively drive interoperable e-health initiatives.

Leadership and governance. Governance provides for the necessary decision making rules and procedures that give direction to, and oversee interoperability initiatives [32]. Without the existence of a governance structure, it is difficult to coordinate e-health initiatives and align them with national health priorities. It also provides the necessary political leadership and facilitates engagement with relevant stakeholders [7.

Strategy and investment. This refers to the development of a national roadmap that guides the coordination of e-health initiatives. The national e-health strategy should be aligned with the country's health priority areas. It should identify interoperability goals and provide a plan of actions to achieve them. Funding for e-health initiatives should also be aligned to the identified interoperability goals [7.

Legislation, policy and investment. In Subsection 2.2, concern for privacy, security and confidentiality of healthcare information was identified as one of the factors affecting widespread adoption of interoperable e-health solutions. These are genuine concerns that have to be addressed through the creation of an appropriate legal framework, which can support effective exchange of healthcare information. Specifically, there should be policies that address e-health interoperability. Such policies should be reviewed on regular basis to ensure that they remain aligned with interoperability objectives. There should also be a mechanism to ensure compliance with interoperability policies [7.

Workforce. This component is required to ensure that the necessary health informatics knowledge and skills are available to implement e-health initiatives. Adequate training and education programmes should be developed in order to build a workforce that is capable of designing, building, and operating interoperable e-health systems, together with the technical expertise to participate in standards development and localization of international standards to meet local requirements [7] 33, 34.

Standards. Standardization is arguably the most critical driver of interoperability [13] [14]. The adoption of e-health standards to support interoperability should be coordinated at national level, preferably through an independent governance structure [35]. Sections 3 and 4 address the standards component in more detail.

Infrastructure. This component creates the physical infrastructure that forms the foundation for the exchange of health information across geographical and health-sector boundaries. Funding should be set aside for the acquisition of physical infrastructures, including the computer hardware and network connectivity that will enable secure exchange of healthcare information [7].

Services and applications. This component represents the tangible means for enabling necessary applications, tools and services that will facilitate secure exchange of health information [7].

\section{THE E-HEALTH STANDARDS DEVELOP- MENT LANDSCAPE}

The formal definition of standard, as defined by the International Organization for Standardization (ISO) is "a document, established by consensus and approved by a recognized body, that provides, for common and repeated use, rules, guidelines or characteristics for activities or their results, aimed at the achievement of the optimum degree of order in a given context" 36 . Simply put, a standard is an agreed-upon, repeatable way of doing something.

Standardization offers a number of benefits, including the prevention of single vendor lock-in, promotion of healthy market competition with associated cost savings, reduction in the risks of new technology development and removing the need for expensive customized solutions [3] 12].

There are many groupings of standards; for example the European Commission [13] identifies four types, namely official, voluntary, industry and open standards while Hatto 37] identified formal, informal and private standards. Although these groupings are relevant within a national or regional context, standards in general fall into two broad groups: proprietary or open.

Proprietary standards are developed for private use by profit-driven industry organizations. Specifications for such standards are typically not disclosed and are subject to copyright law.

Open standards are open for use by all interested stakeholders and can be developed by for profit and non-profit organizations. The standard specifications and necessary documentations are made available for public use, either free of charge or at a nominal fee

E-health standards are developed by SDOs. The remainder of this section provides an overview of the prominent organizations that are involved in e-health standards development.

\subsection{International organisation for standardization}

The International Organization for Standardization is the world's largest developer of standards [38, with 164 national standards bodies across the globe as members. ISO standards are developed by working group members within the various technical committees, which are made up of national member bodies. It offers three categories of membership (full, correspondent and subscriber) and this provides varying degrees of access 


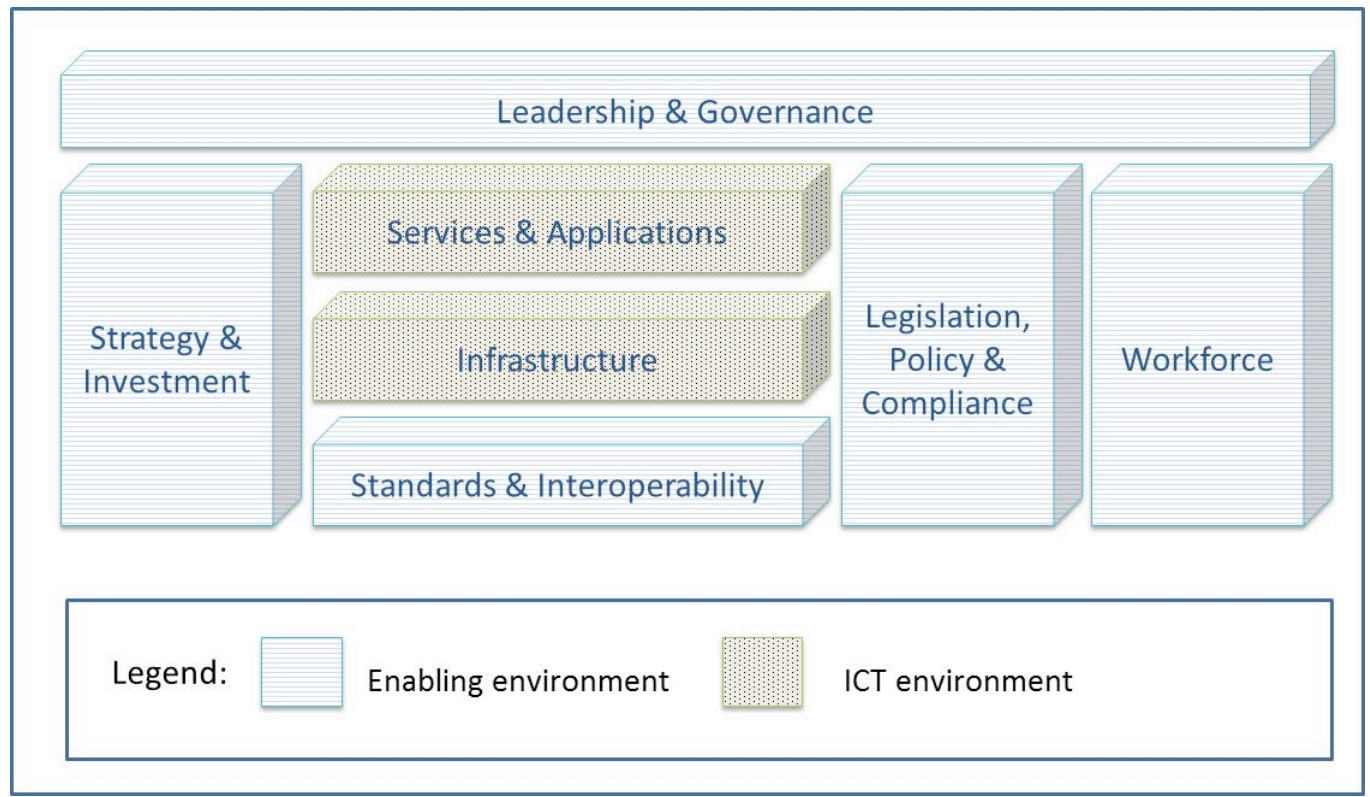

Figure 2: E-health components (adapted from [7])

to ISO's standards, and participation in their development 39. The type of membership that a country holds therefore affects its ability to shape the direction of ISO, and the type of standard it develops.

E-health standards are developed by ISO's health informatics technical committee, ISO/TC 215. The standards are aimed at supporting the growth in the use of ICT in the healthcare domain and facilitating the secure and seamless exchange of health information that is accessible to authorized users as and when required [40].

ISO/TC 215 collaborates with other SDOs and was part of the initiative to establish the Joint Initiative Council (JIC) (see section 3.11) [0].

\subsection{World Health Organisation}

The World Health Organization publishes and maintains the International Classification of Diseases (ICD) codes for classifying diseases, health conditions and causes of death 41, the Anatomical Therapeutic Chemical Classifications Systems with Defined Daily Doses (ATC/DDD) codes for the classification of medicines [42, and the Statistical Data and Metadata Exchange Health Domain (SDMX-HD), a standard for the exchange of healthcare indicators [43, among others.

WHO also collaborates with International Health Terminology Standards Development Organization (IHTSDO) in order to enable cross mapping of the Systematized Nomenclature of Medicine Clinical Terms (SNOMED-CT) terminologies (see section 4.1.2) with ICD codes 44].

\subsection{European Committee for Standardization}

The European Committee for Standardization (CEN) is a non-profit standard development organization comprising of the national standards bodies of the $27 \mathrm{Eu}-$ ropean Union countries, Croatia, the Former Yugoslav
Republic of Macedonia, Turkey, Iceland, Norway, and Switzerland 45. The main goal of CEN is to remove trade barriers across European countries through coordination of the development of European standards, which are in turn adopted as national standards by its member countries. CEN has a cooperation agreement with ISO, aimed at preventing the development of conflicting or parallel standards. With this agreement, an ISO standard could be adopted as a CEN standard, and a CEN standard could be adopted as an ISO standard [45].

CEN e-health standards are developed by the health informatics technical committee, CEN/TC 251 46]. The main focus of the committee is to facilitate the adoption of standards that enable European organizations to achieve optimal use from their investments in health informatics, through the development and adoption of international standards. CENT/TC 251 collaborates with other SDOs, including ISO/TC 215 , Health Level Seven (HL7), The Clinical Data Interchange Standards Consortium (CDISD) and IHTSDO 47.

\subsection{International Health Terminology Standards Development Organization}

The International Health Terminology Standards Development Organization [48] is a non-profit organization that acquired the intellectual property rights to SNOMED-CT clinical terminology database in 2007 [1. The primary goal of IHTSDO is to develop, maintain, and promote the adoption and correct use of SNOMED-CT in the healthcare sector 49]. SNOMED$\mathrm{CT}$ is widely used across the globe, and has a built-in mechanism to cater for local extensions and different languages [50]. 


\subsection{National Electrical Manufacturers Association}

The National Electrical Manufacturers Association (NEMA) 51 is an association of electrical and medical imaging manufacturers. NEMA is the developer of the Digital Imaging and Communication in Medicine (DICOM) standard [52, which facilitates the exchange of digital medical diagnostic images, such as ultrasound, computed tomography (CT) scan and magnetic resonance imaging (MRI) scan between an imaging equipment and other healthcare applications [3] [53.

DICOM has been adopted as an international standard for medical images by ISO under the title ISO 12052:2006 [54]. The standard is developed and maintained by members of the working groups (currently 28), established by the DICOM Standards Committee. Members of the Standards Committee include manufacturers of imaging equipment, suppliers of healthcare solutions, biomedical professional organizations, and other interest groups [55].

\subsection{Health Level Seven}

Health Level Seven is a non-profit, American National Standards Institute (ANSI) accredited organization that develops standards for the exchange of clinical and administrative data among heterogeneous healthcare applications 56. HL7 offers various categories of membership (individual, organizational, supporter/benefactor, caregiver, and student) and the degree of benefits enjoyed is dependent on the type of membership. HL7's 35 international affiliates are mainly from developed nations in Europe, United States and Asian countries, with none from Africa 57.

HL7 standards are developed by volunteers in various working groups, under the stewardship of the technical steering committee [1]. It collaborates with other SDOs, including ISO, CEN, ASTM International, NEMA and IHTSDO 58.

\subsection{Regenstrief Institute}

The Regenstrief Institute is an international informatics and healthcare research organization based at Indiana University and involved in various health-related research activities [59. It aims to enhance the quality and cost-effectiveness of healthcare. The Logical Observation Identifiers Names and Codes (LOINC) coding standard was developed, and is maintained by the Center for Biomedical Informatics Research Group of the Institute.

LOINC is a universal coding system for the reporting of laboratory and clinical observations. Its scope covers laboratory observations, such as chemistry, hematology, serology, microbiology, and urinalysis, as well as clinical observations like vital signs, intake/output, electrocardiogram, endoscopy, and obstetric ultrasound. LOINC is provided free of charge by the developers 60].

\subsection{ASTM International}

ASTM International, formerly known as the American Society for Testing and Materials, is one of many SDOs active in the development of e-health standards 61. During its early inception, the organization was concerned with developing standards for the steel industry, but it has widened its scope to cover other areas of standardization, including e-health. ASTM standards are developed through a consensus process involving a cross-section of interested stakeholders. ASTM committee on Healthcare Informatics (E31) was established in 1970, with the purpose of developing standards that govern the architecture, content, storage, security and communication of healthcare information 62. The committee meets bi-annually. Members of the committee include vendors, clinicians, healthcare institutions and administrators, as well as patient advocates.

\subsection{Integrating the Healthcare Enterprise}

Integrating the Healthcare Enterprise (IHE) is a collaborative initiative involving healthcare professionals and industry stakeholders. The aim of IHE is to improve the manner in which healthcare information is exchanged through the precise definition of healthcare tasks, the specification of standards-based communication between systems that are required to support these tasks, and the testing of systems to determine whether they conform to the required specifications 50. 63.

IHE promotes the coordinated use of established base standards (e.g., ISO, DICOM, HL7, IETF, OASIS, W3C standards) to address specific clinical needs in order to facilitate optimal care 63. This is done through the creation of profiles, which provide precise implementation specifications using the base standards to enable the development of interoperable systems 64 . IHE also collaborates with ISO in e-health standards development through its "Category A" Liaison status with ISO/TC 215 64.

\subsection{Clinical Data Interchange Standards Consortium}

The Clinical Data Interchange Standards Consortium is an international, open, multidisciplinary and non-profit organization involved in the development of standards to support the acquisition, exchange, submission and archive of clinical research data and metadata. The aim of the organization is to develop platform-independent standards that facilitate the interoperability of information systems in order to improve medical research 65. CDISC has collaborative agreement with HL7 to facilitate the harmonization of its clinical research standards and HL7 standards [66].

\subsection{Joint Initiative Council}

The Joint Initiative Council is an alliance between global health informatics SDOs, with the primary goal of addressing the problems associated with gaps, overlaps and contradictions that could arise from the var- 
ious standards that are developed by participating SDOs 67. JIC provides coordination for standards strategies and plans, and aims to make all standards available through ISO. Seven SDOs currently participate in the work programs of JIC, namely, CDISC, CEN/TC 251, GS1, HL7, IHE, IHTSDO, and ISO/TC 215 67. Participation in JIC activities requires an organization to be an international SDO and have a formal relationship with ISO 68 .

\subsection{Institute of Electrical and Electronics Engineers}

The Institute of Electrical and Electronics Engineers (IEEE) is the world's largest professional association and aims to advance technological innovation and excellence for the benefit of humanity 69. IEEE develops standards through a consensus process to facilitate the interoperability of a wide range of products and services. Its healthcare IT standards are targeted at supporting the interoperability of medical devices [70. IEEE has a cooperation agreement with other SDOs, including ISO and the International Electrotechnical Commission (IEC), on joint development of international standards [71].

\subsection{International Electrotechnical Commission}

The International Electrotechnical Commission is a global organization that develops consensus-based standards for the electrotechnology domain. It also manages the assessment of electric and electronic products and services for their conformance to the developed standards 72. Its standards are developed by technical committees, with TC 62 being responsible for developing standards for electrical equipment, electrical systems and software that are used in the healthcare sector 73 .

\subsection{GS1}

GS1 is an international non-profit organization involved in the design and implementation of global standards and solutions aimed at improving the supply and demand chains' efficiencies [74. Its standards are widely used across multiple sectors and industries, including the healthcare, transport, logistics and retail sectors [75. GS1 is a member of the E-health Standardization and Coordination Group within the WHO. This group collaborates with standards organizations to promote stronger coordination among stakeholders in all technical areas of e-health standardization. GS1 also collaborates with ISO/TC 215 76.

\section{THE SIGNIFICANCE OF STANDARDIZA- TION IN E-HEALTH INTEROPERABILITY}

There is consensus that the healthcare domain is highly information intensive and involves the use of large data sets, including multimedia diagnostic images, patient records, test results, research samples, and financial codes 3] 13] 14. These data typically reside in silo systems implemented by each healthcare provider, hospitals, pharmacies, primary care physicians, health insurance funders, and government agencies [14. However, the ability to share information both within and across healthcare institutions is crucial to ensure the delivery of safe, high quality patient-centric healthcare.

Standardization is necessary to make sure that authorized users have access to timely, reliable and accurate information that is vital to the provision of such quality care. For example, from a drug safety perspective, standardization allows a prescriber access to the previous medication and allergy history of patients, as well as information relating to drug-to-drug interactions. It may well be the case that this information is stored in a system external to the current healthcare institution. A system with a standardized interface to a shared health record and clinical decision support systems should be able to access this important information. Thus, a prescription for a drug to which a patient is known to be allergic, or with adverse interaction with a drug which the patient is currently taking, would trigger a warning in the form of an alert, and could avert potentially fatal adverse drug events.

Although standardization is seen as the key to ensuring systems' interoperability, e-health standardization can be challenging for the following reasons 14]:

- The healthcare industry has a huge number of legacy systems, based on proprietary technologies.

- The healthcare domain is one of the most information intensive industries, which may involve huge quantities of data, including multimedia diagnostic images, patient codes, test results, research samples, insurance identifiers, financial codes, and other types of data.

- E-health standards do not necessarily address an integrated area of technology. Rather, they involve several areas, such as standardization at the content level (e.g., patient data, diagnostic images, and medical research); medical device standardization, software systems standardization (e.g., mobile applications and database management systems) process management, infrastructure (e.g., telecommunication systems) and network management (e.g., security, and identification and authentication).

- The e-health standards domain involves competing, and sometimes overlapping standards initiatives taking place in different institutions, many of which charge fees to access or implement standards in products. This practice can drive up the cost of e-health products or discourage innovation based on e-health standards.

From the SDOs reviewed in Section 3, it can be seen that there are several parallel standards development activities happening across the globe. The large number of e-health interoperability standards currently available can make the selection of the appropriate standard(s) difficult, especially for low resource countries in Africa. For example, as just one of the SDOs involved in standardization, ISO/TC 215 has published 
116 standards (including updates) since its creation in 1998 [77].

The remainder of this section presents a classification scheme that could facilitate an understanding of the areas that are addressed by e-health interoperability standards, including: interoperability frameworks and architecture, identifier, messaging / information exchange, structure and content, clinical terminology and coding, electronic health record (EHR), system functional models, and security and access control standards. Section 4.1 presents each of the standard classes, with example(s) of standards that fit into each class, while section 4.2 provides the mapping of a selection of widely used interoperability standards to illustrate their relationship to the levels on interoperability discussed in section 2.1. Because it is impractical to cover the full extent of e-health standards in a single article, we have limited our discussion to the main topic of the paper, i.e., standards that support the interoperability of heterogeneous HISs. Other e-health standards, such as those focusing on mobile health applications and the interoperability of medical devices, are not covered in this paper.

\subsection{Classification scheme for e-health interoperability standards}

The technical report ISO/TR 13054-2012 Knowledge Management of Health Information Standards 78, reviewed different classifications of health information standards and concluded that there is currently no widely accepted classification scheme for e-health standards. To address this gap, work is currently underway through the project ISO/AWI TS 18528 Functional Classification of Health Informatics Standards [79. Examples of the different classification schemes in use include the WHO and ITU classification [7], the classification scheme developed by the Canadian Advisory Committee on Health Infostructure (ACHI) [80, and the Standards Knowledge Management Tool (SKMT) developed by the University of Sherbrook 81. Hammond 82 classified standards necessary for data sharing interoperability as general, data components, data interchange, knowledge representation, electronic health records (EHRs) and application level support standards. Chávez, Krishnan and Gavin [83] grouped the prominent e-health standards as messaging, EHR object model, terminology, and security standards. This section provides a synthesis of the various classification schemes for e-health standards, with a special focus on the standards that support the interoperability of heterogeneous HISs.

Interoperability frameworks and architectures. These are standards that guide the development of e-health systems through the utilization of enterprise architecture (EA) approach such that the ensuing systems are able to support information sharing across organizational boundaries. An example of standards in this group is ISO 12967:2009 (parts 1-3) 84, 85] 86. From developing countries' perspective, a relevant standard in this group is ISO/NP TR 14639-2 Capacitybased eHealth Architecture Roadmap Part 2: Architectural Components and Maturity Model [87, which is still under development.

Identifier standards. These are standards that deal with unique identification of various entities, such as, patients, healthcare providers and healthcare institutions. Examples of these standards include the Identification of subjects of health care (ISO/TS 22220:2011) 88] and the Provider identification (ISO/TS 27527:2010) 89.

Messaging / information exchange standards. These standards specify the structure and format of 'messages' to facilitate secure transmission and receipt of information between healthcare providers. They also specify the acknowledgements that should be sent by the recipient of a 'message', as well as the warnings that should be generated when the 'message' has not be delivered or if it is declined [7. HL7 version 2 messaging standard 90] is the most common way of exchanging healthcare information worldwide [1]. IHE has developed a number of IT infrastructure profiles that address information sharing; these profiles define how lower level standards, including internet and general ICT standards should be configured in order to achieve e-health interoperability.

Structure and content standards. These are standards that provide specification for the structure of the data element in EHRs, referral letters or discharge summaries. The standards also specify the data types, field lengths and the content of data fields in these documents. This is to ensure that healthcare data is presented in a consistent manner by software applications [7. Examples of structure and content standards are HL7 Clinical Document Architecture (CDA) 91, ASTM Continuity of Care Record (CCR) 92, and HL7/ASTM Continuity of Care Document (CCD) 93], which is the harmonization of both HL7 CDA and ASTM CCR standards.

Clinical terminology and coding standards. These support the description of medical conditions, symptoms, diagnosis, and treatments using common language in order to prevent ambiguity in the interpretation of healthcare information that is transmitted electronically [7. Examples of clinical terminology and classification standards include LOINC for coding laboratory test reports 60, ICD codes for classifying diseases, health conditions and causes of death [4], and SNOMED-CT clinical terminology [1].

Electronic health record standards. These are standards that define the architecture of computerized medical records, such as the electronic medical records (EMRs) and EHRs. Examples of EHR standards are the Requirements for an electronic health record architecture (ISO 18308:2011) 94 and ASTM Standard Practice for Description of Reservation/Registration-Admission, Discharge, Transfer (R-ADT) Systems for Electronic Health 
Record (EHR) Systems (ASTM E1239-04:2010) [95.

System functional models. These standards define the range of functionalities that should be supported by EHR systems in different healthcare settings, e.g., primary healthcare, in-patient or out-patient settings. It provides a framework upon which the specifications for a particular EHR system implementation can be based and evaluated. One example of standards in this group is HL7 EHR-System Functional Model, Release 1.1 [96]. The standard has been adopted as an international standard under the title ISO/HL7 10781:2009 [97.

Security and access control standards. These standards enable the secure transmission and delivery of healthcare information so as to ensure that personal healthcare information is protected from unauthorized access [7. Examples of e-health specific security and access control standards are ISO Privilege management and access control (ISO/TS 22600, Parts 1 3) 98 99 [100] and ASTM Standard Guide for User Authentication and Authorization (ASTM E1985-98:2013) [101].

\subsection{Mappings between e-health interoperability standards and the levels of interoperability}

The classification scheme discussed in the previous section is closely aligned to the four levels of interoperability, discussed in Section 2.1. To explain the relationship between the two, this section provides a mapping of a selection of e-health interoperability standards to the four levels of interoperability. We emphasise that the standards discussed in this section are only for illustrative purposes, and the authors have no intention of providing an exhaustive discussion of interoperability standards. First we give a brief description of the standards, and then map the standards to the applicable level(s) of interoperability they support.

ISO 12967:2009 (Health Informatics Service architecture). This is a three-part standard that guides the development of e-health systems and the integration of existing ones to enable information sharing within and across cross an organization. Part one of the standard (Enterprise viewpoint) specifies the required architecture to integrate common data and business logic into a middleware, such that it is separate from individual applications and provides access to 'services' that are available in the entire system [84]. Part two (Information viewpoint) specifies the essential features of the information model to be implemented by a middleware in order to support organizational business processes [85, while part three (Computational viewpoint) defines the vital features of the computational model to be implemented by a middleware to facilitate a comprehensive and integrated interface to the common enterprise information and support organizational business processes [86.
ISO/TS 22220:2011(Health Informatics Identification of subjects of health care). The standard is a specification for the structure and the essential data elements required to positively identify a patient in both ICT-supported and paper-based healthcare environments, as well as the communication of patient information among computer applications. It defines the demographic and other identifying data elements that should be captured, and the guidelines for their implementation in a paper-based or ICT-supported environment 88.

ISO/TS 27527:2010 (Health Informatics Provider identification). The standard is a framework for positive identification of healthcare practitioners and the healthcare institution where the care was provided. It defines the data elements that are required to identify a healthcare practitioner as well as the institution in both paper-based and computerized environments. It also specifies the data elements that enable identification of the individual health provider and organization for the purpose of authorization and authentication of access to health records, the definition of user roles and delegation of authority 89.

HL7 Version 2.X. This is a messaging standard to facilitate the exchange of healthcare data among heterogeneous healthcare systems. Clinical data that can be exchanged in HL7 messages include admission, discharge or transfer (ADT) data, orders and results of laboratory tests, and clinical observations. In addition, administrative data, ranging from appointment schedules and billing information, can also be transmitted in HL7 messages 102 . The first version of the standard, HL7 Version 1 was first published in 1988 [1]. Since then, the standard has undergone several revisions, with the current version being Version 2.7 90]. It is the most widely used messaging standard in the healthcare sector across the globe. It also supports the majority of the common interfaces that are used in the healthcare industry globally, and provides a framework for negotiating what is not supported by the standard. Its high level of flexibility makes it adaptable for any healthcare environment 1] 102. HL7 Version 2 specifies the structure of the messages that are transmitted between HISs. Each message is composed of segments that follow pre-defined sequences. Message segments are made up of fields which hold values for defined data types. The field also follow a defined sequence [1].

HL7 Version 3. HL7 Version 3 standard was developed to address one of the shortcomings of HL7 Version 2, the lack of a consistent application data model due to the flexibility with respect to optional data elements and segments. HL7 Version 3 is based on the Reference Information Model (RIM). The RIM provides an explicit representation of the grammar and semantics of HL7 
Version 3 messages, and models health data using generic classes from which concrete classes can be derived. CDA, discussed later in this section, is the most widely adopted application of HL7 Version 3 across the globe [1].

DICOM. The DICOM standard is a specification for the information object definitions, data structure and their semantics, as well as the protocols for the exchange of medical images between imaging equipment and other healthcare applications, as well as the file format for the storage of medical images 53 .

Statistical Data and Metadata Exchange Health Domain (SDMX-HD). This standard is a specification for the exchange of health indicator definitions, aggregate data and metadata in the healthcare sector. SDMX-HD is a WHO implementation of ISO/TS 17369:2005 SDMX standard, which defines the structure and semantics of the XML mark-up that is contained in SDMX-HD messages [103].

ASTM E2369-12 (Standard Specification for Continuity of Care Record (CCR)). This standard specifies the structure of summary data about the administrative, demographic and clinical information of a subject of care, which can then be transmitted to a healthcare practitioner or a HIS, using XML coding schema. A CCR document can be viewed in a number of ways, including a web browser, as part of an HL7 CDA compliant document, a PDF or word processing document, or in an e-mail message [92.

HL7 Clinical Document Architecture (CDA). This is a document mark-up standard that specifies the structure and semantic of clinical documents, including clinical summaries, discharge notes and investigation (laboratory/radiology) reports. It is based on HL7 Version 3 RIM. The current version of CDA, Release 2, specifies the structure of the header and body of clinical documents to enable human readability while being machine processable at the same time [91] 104]. CDA is the most widely adopted implementation of HL7 Version 3 standard [1].

HL7/ASTM Continuity of Care Document (CCD). HL7/ASTM CCD is an integration of HL7 CDA and ASTM CCR. It provides implementation guidelines for the exchange of a CCR patient summary data using HL7 CDA. Developed through collaboration between ASTM and HL7, it harmonizes the data formats in ASTM CCR and HL7 CDA and provides a set of templates for the various sections of a typical summary record, for example, vital signs, family history and care plan, to facilitate reusability and interoperability 105.

HL7 Care Record Summary (CRS). HL7 CRS is an application of HL7 CDA. It represents the summary of care provided to a patient in the form of discharge, transfer or summary of a care episode. It facilitates the exchange of a summary record between heterogeneous systems through a standard format to report back to a primary care provider or other stakeholders who have interest in a patient's hospital care [106] [107].

SNOMED-CT. This is a clinical terminology database with over 300,000 medical concepts that represent clinical information. SNOMED-CT facilitates semantic interoperability through the use of standardized clinical concepts and terminologies [50]. Each concept in SNOMED-CT is organized in hierarchies, which are linked to other concepts through relationships. This allows clinical information to be captured at the required level of detail. SNOMED-CT also supports cross mapping to other clinical terminology and coding schemes, for example, ICD-10, this enables the re-use of coded data for purposes other than originally intended, for example, medical claims reimbursement [1] [50].

LOINC. This is a clinical coding system that enables the exchange of laboratory results. It facilitates interoperability through the use of a set of universal codes and names for the identification of laboratory test results and clinical observations 50. 60.

International Classification of Diseases (ICD). ICD is an international coding system for classifying diseases, health conditions and the causes of death. It facilitates the compilation of vital health statistics, including morbidity and mortality, as well as medical care reimbursement. ICD supports interoperability through the use of standard codes for disease conditions [41] 108.

International Classification of Primary Care, Second edition (ICPC-2). This is a clinical classification system, originally developed by the World International Classification Committee (WICC) and adopted by the WHO, for the classification of a patient's reason for encounter, the diagnosis, interventions, and the ordering of the data in the care episode structure. ICPC-2 can be utilized both in primary health care and general practice settings [109].

Current Procedural Terminology (CPT). This is a coding system that was developed and maintained by the American Medical Association (AMA). It facilitates the exchange of clinical information among healthcare providers and medical aid administrators through the use of a uniform coding scheme for medical and surgical procedures 110 111.

ISO 21090:2011 (Harmonized data types for information interchange). The standard provides a specification for the data types of the basic concepts in the healthcare domain to enable the exchange of healthcare information. It extends the datatypes defined in ISO/IEC 11404 standard by specifying their meanings, using the terminologies, notations and the datatypes defined in ISO/IEC 11404 [112. 
ISO 18308:2011 (Requirements for an electronic health record architecture). The standard specifies the requirements for an EHR architecture such that the implemented EHR system is capable of fulfilling the needs of healthcare delivery, is clinically valid and reliable, ethically sound, compliant with the prevailing legal requirements, supports good clinical practice, and enables data analysis for a variety of purposes 94 .

HL7 EHR-System Functional Model, Release 1.1. This standard provides a reference list of the functionalities that may be provided in an EHR system. These are provided from a user's perspective in order to facilitate a consistent description of system functionalities that should be provided in a specific healthcare setting [96].

ISO/TS 22600 (Privilege management and access control). This is a three-part standard that provides a mechanism for the management of user privileges and the control of access to healthcare information. It supports the need for the exchange of healthcare information among healthcare practitioners, institutions, health insurance companies, patients, and other personnel [98, 99, [100].

As discussed in Section 2.1, interoperability can be achieved at a technical, syntactic, semantic or organizational level. It is noteworthy that technical and syntactic interoperability is relatively easy to achieve, and largely do not constitute a problem. The challenge for the healthcare domain is semantic interoperability, which has proved to be difficult for the reasons provided in Section 2.3. Because of the genuine concern for semantic interoperability, the majority of the standards discussed in this section are aimed at facilitating semantic interoperability.

Table 1 provides a mapping of these standards to the applicable level(s) of interoperability. 'Messaging' standards are generally aimed at supporting syntactic interoperability through the transmission of structured 'messages', while those classified under structure and content address interoperability both at the syntactic and semantic levels by specifying the structure of clinical documents that contain both coded and free text data. Clinical terminologies and codes are used to prevent ambiguity in the use of medical terms, thereby ensuring the same interpretation of clinical data, irrespective of the application that is receiving the data.

ISO/TS 27527:2010 [89] and ISO 18308:2011 [94] address elements of syntactic, semantic and organizational interoperability. In the case of ISO/TS 27527:2010, issues that relate to positive identification of health providers and facilities, as well as organizational rules for assigning user roles for the purpose of accessing patients' medical records are covered, while ISO 18308:2011 focusses on the specifications for a shareable EHR system, which requires a mechanism to address the content and structure of an EHR, as well as various issues that relate to organizational policies for access.

However, HL7 EHR-System Functional Model, Release 1.1, could potentially address all four levels of interoperability. It covers functionalities that include the ability of an EHR system 96.

- To transmit an EHR data using secure routing protocols (technical).

- To support requirements for a specific data format and structure as required by a particular healthcare organization (syntactic).

- To utilize standard terminologies to enable sematic interoperability (semantic).

- To provide support for the management of organizational business rules (organizational).

\section{OVERVIEW OF E-HEALTH STANDARDS ADOPTION AND IMPLEMENTATION IN AFRICA}

To conclude the discussion on interoperability standards for e-health, we contextualize the discussion by focusing on the health information system and interoperability adoption landscape in Africa. It should be noted that the level of e-health standards adoption is currently under-researched in Africa; with little or no published research available. In general, the healthcare information system implementation in Africa lacks coordination especially at national level, with many implementations being driven by donor-funded vertical programmes such as HIV/AIDS and tuberculosis, monitoring and evaluation 33. The degree of this fragmentation is succinctly captured in a foreword to the eHealth Strategy South Africa document by the country's Minister of Health:

Historically, health information systems in South Africa have been characterized by fragmentation and lack of coordination, prevalence of manual systems and lack of automation, and where automation existed, there was a lack of interoperability between different systems. 113 .

In addition, a number of studies on e-health systems in Africa revealed that several of the implementations were mere pilot projects at single facilities, with no evidence of scaling up 114 115. Many of these vertical systems are also not capable of exchanging healthcare data to support continuity of care 116.

When it comes to e-health standards adoption at national level, there is no evidence of e-health standards adoption other than ICD codes. Notable exceptions are Kenya, which has mandated the use of ICD-10 or SNOMED-CT as terminology standard, HL7 messages for the exchange of laboratory and radiology results, HL7 CDA for the exchange of clinical summaries, and ISO/TS 22220 as the basis of its patient demographics [117, and Rwanda, which has adopted HL7 Version 2 as its messaging standard [18. It is also noteworthy that the South African National Department of Health has embarked on the development of a normative standards framework for e-health. The aim of this initiative is to guide the adoption of appropriate e-health interoperability standards that could support information sharing to facilitate continuity of care. 
Table 1: Standards and interoperability level mappings

\begin{tabular}{|c|c|c|c|c|}
\hline & \multicolumn{4}{|c|}{ Interoperability level } \\
\hline Standard & technical & syntactic & semantic & organizational \\
\hline \multicolumn{5}{|c|}{ Identifiers } \\
\hline ISO/TS 22220:2011 & & $\mathrm{X}$ & $\mathrm{X}$ & \\
\hline ISO/TS 27527:2010 & & $\mathrm{X}$ & $\mathrm{X}$ & $\mathrm{X}$ \\
\hline \multicolumn{5}{|c|}{ Messaging / information exchange } \\
\hline HL7 V2.X & & $\mathrm{X}$ & $\mathrm{X}$ & \\
\hline HL7 V3 & & $\mathrm{X}$ & $\mathrm{X}$ & \\
\hline DICOM & & $\mathrm{X}$ & $\mathrm{X}$ & \\
\hline SDMX-HD & & $\mathrm{X}$ & & \\
\hline \multicolumn{5}{|c|}{ Structure and content } \\
\hline ASTM E2369-12 & & $\mathrm{X}$ & $\mathrm{X}$ & \\
\hline HL7 CDA & & $\mathrm{X}$ & $\mathrm{X}$ & \\
\hline HL7/ASTM CCD & & $\mathrm{X}$ & $\mathrm{X}$ & \\
\hline HL7 CRS & & $\mathrm{X}$ & $\mathrm{X}$ & \\
\hline ISO 21090 & & $\mathrm{X}$ & $\mathrm{X}$ & \\
\hline \multicolumn{5}{|c|}{ Clinical terminology and coding } \\
\hline SNOMED & & $\mathrm{X}$ & $\mathrm{X}$ & \\
\hline LOINC & & $\mathrm{X}$ & $\mathrm{X}$ & \\
\hline ICD & & $\mathrm{X}$ & $\mathrm{X}$ & \\
\hline ICPC-2 & & $\mathrm{X}$ & $\mathrm{X}$ & \\
\hline $\mathrm{CPT}$ & & $\mathrm{X}$ & $\mathrm{X}$ & \\
\hline \multicolumn{5}{|c|}{ Electronic health record } \\
\hline ISO 18308:2011 & & $\mathrm{X}$ & $\mathrm{X}$ & $\mathrm{X}$ \\
\hline \multicolumn{5}{|c|}{ System functional models } \\
\hline $\begin{array}{l}\text { HL7 EHR-System Func- } \\
\text { tional Model, Release } 1.1\end{array}$ & $\mathrm{X}$ & $\mathrm{X}$ & $\mathrm{X}$ & $\mathrm{X}$ \\
\hline \multicolumn{5}{|c|}{ Security and access control } \\
\hline ISO/TS 22600 & & & & $\mathrm{X}$ \\
\hline
\end{tabular}

E-health system implementations in many African countries are incapable of sharing crucial healthcare information that is necessary to support continuity of care. The prevalence of non-interoperable healthcare systems in Africa is closely linked to the low level of e-health standards adoption, especially at national level.

Having highlighted the important role of standardization in enabling interoperability, the question that could be asked is why are African countries not adopting e-health standards that could support interoperable HISs? The remainder of this section examines some of the factors that contribute to the low level of e-health interoperability standards adoption in Africa.

Our literature analysis revealed that the slow pace of the adoption of standards (both by developed and developing nations) is due to several factors. The factors include the large number of standards that are being developed by the various SDOs, the fact that e-health standards do not address one unified area of technology, the existence of conflicting and overlapping standards, the difficulty of combining standards from different SDOs, and the high cost of converting to new standard-based solutions [13] [50]. However, our analysis of the literature revealed that developing countries also face additional challenges when compared to developed countries, including:

- Limited participation in standards development process.

- Lack of human resource capacity for standards development.

- Lack of appropriate experience in the use of standards.

- Lack of understanding of the importance of standards at national level.

- Lack of foundational infrastructure.

- Lack of implementation guidelines.

We discuss each of these challenges in more detail below.

\subsection{Limited participation in standards development}

As stated in Section 3.1, ISO is the world's largest developer of standards, and the type of membership that a country holds is directly related to the country's ability to shape the direction of ISO, and the type of standard it develops. Among the 164 national standards bodies represented on ISO, 111 countries hold full membership. However, only 20 of these are from Africa 119 .

More specifically, participation in the activities of ISO/TC 215 by African countries is quite limited. This committee has 58 member countries, but only three African countries (Kenya, South Africa and Tunisia) are participating members, while Zimbabwe holds observing membership [120]. Limited participation of 
African countries in this committee could be as a result of the cost associated with each type of membership [121, as well as the high cost of sending a delegation to attend meetings that are held bi-annually. There are significant cultural and environmental differences between developed and developing nations. Low level representation of African countries in standards development means that the continent's ability to influence the development of standards that address their peculiar needs, is greatly reduced [121.

\subsection{Lack of human resource capacity for standards development}

African countries generally have low levels of human resources with the requisite expertise to participate in standards development [122]. The adoption of international e-health standards by a country almost always requires significant localization to meet the specific requirements of the country. Given that there is limited capacity and participation, due to resource reasons, the African context is not brought to the fore, and this could result in a gap between what is produced and what is required in the African context. This could make localization much more difficult and expensive. Furthermore, inadequate technical expertise could lead to an absence of, or ineffective government policies regarding the adoption of e-health standards [121.

\subsection{Lack of appropriate experience in the use of standards}

E-health standards are typically developed by technical and standards experts in the various working groups of an SDO. However, the resulting standards from this highly technical specification process would be relevant to a diverse range of end-users, from the technically savvy healthcare application developers to policy makers in government, who may want to use the standards as a basis for the country's e-health strategy [123. Lack of appropriate experience in the interpretation and use of standards could result in incorrect implementation from that intended by the developers of the standards.

\subsection{Lack of understanding of the importance of standards at national level}

Healthcare systems in Africa are largely paper-based. Where ICT is in use, it is mainly to support data capturing, storage, retrieval, monitoring and evaluation of health programmes sponsored by external donors. Although governments remain highly significant stakeholders in the healthcare sector, many African countries have no policies and strategies to govern e-health initiatives at a national level 33 .

When compared to developed nations like the European Union, Africa has no known policy framework that governs areas of common interest at continental level. Notable in this regard is the European Patient Smart Open Systems (epSOS) project, which provides for the development of interoperable EHR systems across Europe in order to improve the quality of crossborder healthcare services for its citizens [124.

Furthermore, many of the high-level government officials who make policy decisions regarding e-health initiatives do not understand the important role of standards in effecting quality care. This could be due to the technical nature of standardization [121].

\subsection{Lack of foundational infrastructure}

Many African nations have a large number of its citizens living in rural areas. In the majority of cases, these rural communities lack even the most basic infrastructure, such as, electricity. There is also limited ICT infrastructure. Broadband Internet connectivity is very low compared to developed countries. Foundational infrastructures, such as patient and provider registries, as well as common terminology services are largely absent. Where ICT infrastructures are in place, they are neither standardized nor based on common platforms, making it difficult for them to interoperate 33 .

\subsection{Lack of implementation guidelines}

Many of the available standards do not have implementation guidelines [50]. The efforts to 'translate' standards to implementable systems often require interaction between experts. Inadequate implementation expertise could affect the ability of local developers to implement standards-based healthcare systems.

\section{OVERCOMING THE BARRIERS TO E- HEALTH STANDARDS ADOPTION}

The adoption of e-health standards ensures that healthcare information is accessible to authorized users as and when required 77. However, one of the barriers to the adoption of e-health standards relates to the difficulty of selecting the 'right' standard(s) from the large number of, and sometimes conflicting, standards that have been published. For example, both the ASTM CCR and HL7 CDA standards were developed to support the exchange of clinical documents. Which one should be used? To conclude the paper we analyze the initiatives to overcome the barriers to the adoption of e-health interoperability standards.

In recent years, several initiatives were undertaken by SDOs to coordinate and harmonize existing standards to assist with such difficulties, as well as with future standards development efforts 125. An example of such initiative to harmonize competing standards led to the development of HL7/ASTM CCD 93] from ASTM CCR and HL7 CDA standards.

As discussed in Subsection 5.1, there is limited participation by African countries in e-health standards development process. One reason for this limited participation has to do with the overall costs of such participation. Many of the SDOs charge fees for the various types of membership. Furthermore, attending meetings of the technical committees could be costly, especially for a low resource country. The 
transformation of the standards development process at the international level is long overdue. To improve the level of participation in standards development, SDOs should significantly reduce membership fees for African and developing countries. Furthermore, the cost of accessing standards should not be prohibitive.

Implementation of many standards in software solutions typically attracts licensing fees. There are on-going efforts by SDOs to make access to standards more affordable. For example, IHTSDO provides licenses for the use of SNOMED-CT free of charge to 40 countries classified as low economies, 26 of these countries are from Africa [126]. Likewise, HL7 has since the beginning of April 2013 started to make HL7's primary standards and other selected intellectual property (IP) available at no cost [127.

Inadequate human resource capacity remains a critical challenge to the adoption of e-health in general, and e-health standards in particular. The WHO and ITU eHealth Strategy Toolkit [] and the Draft Policy for Harmonization of eHealth Initiative in Africa 33 both recommend the development of effective health ICT workforce, capable of designing, building, operating and supporting e-health services. This workforce should lead to professionals with the requisite technical expertise to participate in standards development, as well as the localization of international standards to fit a country's specific need. This will enable African countries to leverage ICT in healthcare delivery.

In recent years, there have been increasing efforts among SDOs to assist low and middle income countries (LMICs) to fill the human resource capacity gap that is necessary for standards adoption. For example, in 2011 ISO/TC 215 established the Public Health Task Force (PHTF) with the following objectives:

1. identify the most effective method of promoting access to e-health standards by LMICs;

2. identify the standards gaps in LMICs;

3. recommend ways to accelerate the rate of e-health standards adoption, adaption and implementation among LMICs;

4. identify ways to facilitate LMICs' participation in ISO activities;

5. advise and provide guidance to LMICs on standards adoption [128.

According to discussions with an expert on PHTF, the PHTF task force is in the process of evaluating the current state of e-health standards in the public health sectors of LMICs. However, our discussions revealed that while some members of the task force are from developing countries, very few are from Africa. In addition, the expert noted that meetings of the task force, held via conference calls, generally take place at time periods that are at odds with African countries' time zones.

Another human capacity building initiative is the HL7 International Mentoring Committee, which aims to assist potential and existing HL7 affiliate organizations with suitable guidance and education, to enable them improve their processes and procedures sufficiently to become viable affiliate organizations [129].
In addition to limited access to e-health standards, the absence of implementation guidelines for many of the published standards makes it difficult for countries with limited technical expertise to incorporate e-health standards in the applications they develop. IHE is addressing this problem through the creation of profiles that guide the implementation of interoperable systems. IHE, an initiative by healthcare professionals and industries, aims to promote the coordinated use of e-health standards to address a specific clinical requirement 63. However, participation in IHE activities is also largely dominated by multinational organizations, healthcare professional organizations from developed countries as well as regional/national bodies from Europe, Asia-Oceania and North America 130. There is a need for health informatics stakeholders from Africa and other developing countries to be involved in IHE activities so that their special interests can be represented.

As an important stakeholder in the healthcare domain, African governments need to play an active role in the adoption of e-health standards. At national level, there should be policies governing the acquisition of e-health solutions. Investment in foundational ICT infrastructures should be prioritized to facilitate the deployment of standards-based interoperable solutions.

\section{CONCLUSION}

The full benefits of e-health systems' implementation depend on their ability to exchange crucial healthcare information to support quality healthcare services. Standardization is at the heart of interoperable HISs. However, significant barriers impede wide-spread adoption of e-health standards, especially by African countries. These barriers include lack of understanding of the importance of standards at a high level, limited participation in standards development, lack of appropriate experience in the use of standards, cost barriers to accessing standards, lack of foundational infrastructures, and limited human resource capacity for standard development and localization.

Overcoming these barriers will require transformation of standards development process at an international level. African governments would have to prioritize investment in basic infrastructure and the development of human resource capacity. Governments should also play a more active role in standards adoption through appropriate national policies and guidelines.

\section{REFERENCES}

[1] T. Benson. Principles of health interoperability HL7 and SNOMED. Springer, 2010.

[2] Ireland Health Information and Quality Authority. "Developing National eHealth Interoperability Standards for Ireland: A Consultation Document". Available from: http://alturl.com/k63ut, 2011. 
[3] K. A. Wager, F. W. Lee and J. P. Glaser. Health care information systems: a practical approach for health care management. Wiley.com, 2009.

[4] WHO. "eHealth Standardisation and Interoperability". Available from: http://goo.gl/O1Buv, 2013.

[5] J. A. Blaya, H. S. Fraser and B. Holt. "E-health technologies show promise in developing countries". Health Affairs, vol. 29, no. 2, pp. 244-251, 2010.

[6] OECD. "Improving Health Sector Efficiency: The Role of Information and Communication Technologies". Available from: http://goo.gl/hQn7B, 2010.

[7] WHO and ITU. "National eHealth Strategy Toolkit". Available from: http://goo.gl/uxMvE, 2012.

[8] Australian Government Department of Health and Aging. "National E-health Strategy". Available from: http://goo.gl/OkfGD, 2008.

[9] J. G. Anderson. "Social, ethical and legal barriers to ehealth". International journal of medical informatics, vol. 76 , no. 5, pp. 480-483, 2007.

[10] B. Moniz. "Examining the unintended consequences of computerized provider order entry system implementation". Online Journal of Nursing Informatics (OJNI), 2009

[11] M. Meingast, T. Roosta and S. Sastry. "Security and privacy issues with health care information technology". In Engineering in Medicine and Biology Society, 2006. EMBS'06. 28th Annual International Conference of the IEEE, pp. 5453-5458. IEEE, 2006.

[12] ITU. "Standards and eHealth". Available from: http://alturl.com/tygq9, 2011.

[13] European Commission. "ICT Standards in the Health Sector: Current Situation and Prospects". Available from: http://goo.gl/KOKZn, 2008.

[14] ITU. "E-health standards and interoperability". Available from: http:/alturl.com/xonvr, 2012.

[15] IDABC. "European Interoperability Framework for Pan-European eGovernment Services". Available from: http://goo.gl/5SD7R, 2004

[16] HIMSS. "Definition of interoperability". Available from: http://goo.gl/E5636, 2013.

[17] P. Gibbons, N. Arzt, S. Burke-Beebe, C. Chute, G. Dickinson, T. Flewelling, T. Jepsen, D. Kamens, J. Larson, J. Ritter et al. "Coming to terms: Scoping interoperability for health care". Available from: http://goo.gl/XzRER, 2007.

[18] W. Wang, A. Tolk and W. Wang. "The levels of conceptual interoperability model: applying systems engineering principles to M\&S". In Proceedings of the 2009 Spring Simulation Multiconference, p. 168. Society for Computer Simulation International, 2009.

[19] L. E. Whitman and H. Panetto. "The missing link: Culture and language barriers to interoperability". Annual Reviews in Control, vol. 30, no. 2, pp. 233241, 2006.

[20] European Telecommunication Standards Institute. "Achieving Technical Interoperability - the ETSI Approach". Available from: http://goo.gl/lQYd4, 2008.

[21] European Commission. "Discussion Paper on Semantic and Technical Interoperability". Available from: http://goo.gl/dJuZ4, 2012.
[22] European Coordination Committee of the Radiological Electromedical and Healthcare IT Industry. "Introduction to Interoperability: Improving the Seamless flow of Information between Medical Disciplines, Health Systems, Regions and Countries for better Healthcare". Available from: http://goo.gl/oXlk9, 2012.

[23] R. Kaushal, L. M. Kern, Y. Barrón, J. Jill Quaresimo and E. L. Abramson. "Electronic prescribing improves medication safety in community-based office practices". Journal of general internal medicine, vol. 25, no. 6, pp. 530-536, 2010.

[24] L. Kun. "Interoperability: the cure for what ails us [Government Affairs]". Engineering in Medicine and Biology Magazine, IEEE, vol. 26, no. 1, pp. 87-90, 2007.

[25] J. Halamka, J. M. Overhage, L. Ricciardi, W. Rishel, C. Shirky and C. Diamond. "Exchanging health information: local distribution, national coordination". Health Affairs, vol. 24, no. 5, pp. 1170-1179, 2005.

[26] A. S. O'Malley, J. M. Grossman, G. R. Cohen, N. M. Kemper and H. H. Pham. "Are electronic medical records helpful for care coordination? Experiences of physician practices". Journal of general internal medicine, vol. 25, no. 3, pp. 177-185, 2010.

[27] WHO. "66th World Health Assembly: eHealth Standardization and Interoperability". Available from: http://goo.gl/UJsx5, 2013.

[28] Future Identity in the Information Society. "Barriers for interoperability". Available from: http://goo.gl/QopaJ, n.d.

[29] F. B. Vernadat. "Technical, semantic and organizational issues of enterprise interoperability and networking". Annual Reviews in Control, vol. 34, no. 1, pp. 139-144, 2010.

[30] K. Rosati and M. Lamar. "The Quest for Interoperable Electronic Health Records: A Guide to Legal Issues in Establishing Health Information Networks". Available from: http://goo.gl/zALFm, 2005.

[31] K. A. Stroetmann, J. Artmann, J. Dumortier and G. Verhenneman. "United in Diversity: Legal challenges on the road towards interoperable eHealth solutions in Europe". EJBI, vol. 8, no. 2, pp. 3-10, 2012.

[32] T. Pardo and G. B. Burke. IT Governance Capability: Laying the foundation for government interoperability. Research Foundation of State University of New York, 2009 .

[33] Anon. "A draft policy for harmonization of eHealth initiatives in Africa". Available from: http://goo.gl/qsIYf, 2010.

[34] mHealth Alliance. "The State of Standards and Interoperability for mHealth among Lowand Middle-Income Countries". Available from: http://goo.gl/8Q440, 2013.

[35] American Health Information Management Association. "Health Information and Communication Investment Recommendations". Available from: http://goo.gl/6wfnx, 2009.

[36] ISO. "ISO/IEC Guide 2:2004 - Standardization and Related Activities - General Vocabulary". Available from: http://goo.gl/f7P5n, 2004. 
[37] P. Hatto. "Standards and standardisation: A practical guide for researchers". Available from http://alturl.com/ipq6x, 2011.

[38] ISO. "About ISO". Available from: http://goo.gl/hO5qe, n.d.

[39] ISO. "ISO Membership Manual". Available from: http://goo.gl/lbnqy, 2012.

[40] ISO. "Business Plan: ISO/TC 215 Health Informatics". Available from: http://goo.gl/Xe7y4, 2013.

[41] WHO. "International classification of diseases (ICD)". Available from: http://goo.gl/dVNN, 2013.

[42] WHO Collaborating Centre for Drug Statistics Methodology. "Anatomical Therapeutic Chemical /Defined Daily Dose: Structure and Principles". Available from: http://goo.gl/LXaRA, 2011.

[43] SDMX-HD. "Statistical Data and Metadata Exchange-Health Domain Standard Specification". Available from: http://goo.gl/cyq95, n.d.

[44] WHO. "SNOMED CT to ICD-10 cross-map technology preview release". Available from: http://goo.gl/o0d8s, n.d.

[45] European Committee for Standardization. "Hands on Standardization: A Starter Guide for Experts in CEN Technical Bodies". Available from: http://goo.gl/m7L9W, 2012.

[46] European Committee for Standardization. "Health Informatics - Published Standards". Available from: http://goo.gl/MMXY3, 2009.

[47] CEN/TC 251. "CEN/TC 251: Business Plan". Available from: http://goo.gl/5pxCv, 2010.

[48] IHTSDO. "Welcome to IHTSDO". Available from: http://www.ihtsdo.org/, n.d.

[49] IHTSDO. "Frequently Asked Questions". Available from: http://goo.gl/8qjna, n.d.

[50] CEN/CENELEC. "eHealth-INTEROP Report in response to eHealth Interoperability Standards Mandate". ETSI, 2009.

[51] National Electrical Manufacturer Association. "About the National Electrical Manufacturer Association". Available from: http://goo.gl/IPL7b, n.d.

[52] National Electrical Manufacturer Association. "About DICOM". Available from: http://goo.gl/cSG7A, n.d.

[53] National Electrical Manufacturer Association. "Digital Imaging and Communications in Medicine (DICOM) Part 1: Introduction and Overview. (2011)". Available from: http://goo.gl/SpbNk, 2011.

[54] ISO. "ISO 12052:2006 - Digital imaging and communication in medicine (DICOM) including workflow and data management". Available from: http://goo.gl/yPd1e, 2006.

[55] National Electrical Manufacturer Association. "Members of the DICOM Standards Committee". Available from: http://goo.gl/mXpCF, 2012.

[56] Health Level 7. "About HL7". Available from: http://goo.gl/NAWNm, n.d.

[57] Health Level 7. "International Council". Available from: http://goo.gl/BYtft, n.d.
[58] Health Level 7. "HL7 Backgrounder Brief: HL7 is the Worldwide Leader in Interoperability Standards". http://goo.gl/Nb20o, n.d.

[59] Regenstrief Institute. "Regenstrief Institute: About Us". Available from: http://goo.gl/jZYu9, 2013.

[60] C. J. McDonald, S. M. Huff, J. G. Suico, G. Hill, D. Leavelle, R. Aller, A. Forrey, K. Mercer, G. DeMoor, J. Hook et al. "LOINC, a universal standard for identifying laboratory observations: a 5-year update". Clinical chemistry, vol. 49, no. 4, pp. 624-633 2003.

[61] ASTM International. "Welcome to ASTM". Available from: http://goo.gl/oGXrP, n.d.

[62] ASTM International. "ASTM Committee E31 on Healthcare Informatics." Available from: http://goo.gl/MrByp., n.d.

[63] Integrating the Healthcare Enterprise. "Welcome to Integrating the Healthcare Enterprise". Available from: http://www.ihe.net/, 2012.

[64] Integrating the Healthcare Enterprise. "IHE International gains official ISO Liaison Status". Available from: http://goo.gl/v4wky, 2011.

[65] Clinical Data Interchange Standards Consortium. "CDISC: Mission and principles". Available from: http://goo.gl/Wt7HN, 2013.

[66] Clinical Data Interchange Standards Consortium. "CDISC: FAQ". Available from: http://goo.gl/yWkkz, 2013.

[67] Joint Initiative Council. "Joint Initiative on SDO Global Health Informatics Standardization". Available from: http://goo.gl/Kum5d, n.d.

[68] Joint Initiative Council. "Requirements for membership in Joint Initiative Council". Available from: http://goo.gl/qAapg, 2008.

[69] IEEE. "About IEEE". Available from: http:/goo.gl/i1Zsu, 2013.

[70] IEEE. "IEEE: Healthcare IT standards". Available from: http://goo.gl/ahz3u, 2013.

[71] IEEE. "IEEE: Formal Liaisons". Available from: http://goo.gl/DLZl8, 2013.

[72] IEC. "About the IEC". Available from: http://goo.gl/YqkBX, 2013.

[73] IEC. "TC 62: Electrical Equipment in Medical Practice". Available from: http://goo.gl/LWcJx, 2013.

[74] GS1. "GS1: Overview". Available from: http://goo.gl/ATb0b, n.d.

[75] GS1. "GS1: Sectors and Collaborations". Available from: http://goo.gl/a1FZI, n.d.

[76] GS1. "GS1: Collaborations - Healthcare". Available from: http://goo.gl/Vzbww, n.d.

[77] ISO. "About ISO/TC 215 Health Informatics". Available from: http://goo.gl/8AeFh, n.d.

[78] ISO. "ISO/TR 13054:2012 - Knowledge Management of Health Information Standards". Available from: http://goo.gl/hx771, 2012.

[79] ISO. "ISO/AWI TS 18528 - Functional Classification of Health Informatics Standards (Under development)". Available from: http://goo.gl/OpvwV, n.d. 
[80] Pan-Canadian Standards Collaborative. "The EHR Standards Map and Responsibilities for Delivering Standards". Available from: http://goo.gl/EDZGx, 2005.

[81] Collaborative Research for Effective Diagnostics. "Spider: Visual Exploratory Tool Supporting HIS-KR and SKMT". Available from: http://goo.gl/lJ7M5, 2011.

[82] W. E. Hammond. "The making and adoption of health data standards". Health Affairs, vol. 24, no. 5, pp. 1205-1213, 2005.

[83] E. Chávez, P. Krishnan and G. Finnie. "A taxonomy of e-health standards to assist system developers". In Information Systems Development, pp. 737-745. Springer, 2010.

[84] ISO. "ISO 12967-1:2009 - Service Architecture Part 1: Enterprise Viewpoint". Available from: http://goo.gl/fWuki, 2009.

[85] ISO. "ISO 12967-2:2009 - Service Architecture Part 2: Information Viewpoint". Available from: http://goo.gl/EY61x, 2009.

[86] ISO. "ISO 12967-3:2009 - Service Architecture Part 3: Computational Viewpoint". Available from: http://goo.gl/51aMJ, 2009.

[87] ISO. "ISO/NP TR 14639-2:Capacity-based eHealth Architecture Roadmap - Part 2: Architectural Components and Maturity Model (Under development)". Available from: http://goo.gl/mWzH6, n.d.

[88] ISO. "ISO/TS 22220:2011 - Identification of Subjects of Health Care". Available from: http://goo.gl/iSW1U, 2011.

[89] ISO. "ISO/TS 27527:2010 - Provider Identification". Available from: http://goo.gl/uV3D2, 2010.

[90] Health Level 7. "HL7 Version 2 Product Suite". Available from: http://goo.gl/AK3dB, n.d.

[91] Health Level 7. "CDA Release 2". Available from: http://goo.gl/2bxqQ, n.d.

[92] ASTM International. "ASTM E2369 - 12 Standard Specification for Continuity of Care Record (CCR)". Available from: http://goo.gl/PwnfY, 2013.

[93] Health Level 7. "HL7/ASTM Implementation Guide for CDA Release 2 -Continuity of Care Document: Release 1". Available from: http://goo.gl/Z3A6y, 2013.

[94] ISO. "ISO 18308:2011 - Requirements for an Electronic Health Record Architecture". Available from: http://goo.gl/s9Pam, 2011.

[95] ASTM International. "ASTM E1239 - 04 (2010): Standard Practice for Description of Reservation/Registration-Admission, Discharge, Transfer (R-ADT) Systems for Electronic Health Record (EHR) Systems." Available from: http://goo.gl/f4mvj, 2010.

[96] Health Level 7. "HL7 EHR-System Functional Model, R1.1 - Chapter 1: Overview", 2012.

[97] ISO. "ISO/HL7 10781:2009 - Electronic Health Record-System Functional Model, Release 1.1". Available from: http://goo.gl/b3kE8, 2009.

[98] ISO. "ISO/TS 22600-1:2006 - Privilege Management and Access Control - Part 1: Overview and Policy Management". Available from: http://goo.gl/KihXf, 2006.
[99] ISO. "ISO/TS 22600-2:2006 - Privilege Management and Access Control - Part 2: Formal Model". Available from: http://goo.gl/DcLUw, 2006.

[100] ISO. "ISO/TS 22600-3:2009 - Privilege Management and Access Control - Part 3: Implementations". Available from: http://goo.gl/AmnJd, 2009.

[101] ASTM International. "ASTM E1985-98 (2013): Standard guide for user authentication and authorisation". Available from: http://goo.gl/UhjBY, 2005.

[102] CEN/CENELEC. "eHealth-INTEROP Report: Annex A, Inventory of Standards." ETSI, 2009.

[103] SDMX-HD. "Statistical Data and Metadata Exchange-Health Domain Standard v1.0". Available from: http://goo.gl/8WKM3, 2010.

[104] R. H. Dolin, L. Alschuler, S. Boyer, C. Beebe, F. M. Behlen, P. V. Biron and A. S. Shvo. "HL7 clinical document architecture, release 2". Journal of the American Medical Informatics Association, vol. 13, no. 1, pp. 30-39, 2006.

[105] Health Level 7. "Continuity of Care Document". Available from http://goo.gl/4URf6, 2010.

[106] K. Boone. "Care record summary: Implementation guides for CDA release 2". Available from: http://goo.gl/C1qeQ, 2005.

[107] Health Level 7. "HL7 Implementation Guide for CDA Release 2: Care Record Summary Discharge Summary". http://goo.gl/w8WKC, n.d.

[108] Medicity. "A Semantic Foundation for Achieving HIE Interoperability". Available from: http://goo.gl/GG7h3, 2010.

[109] WHO. "International classification of primary care, second edition (ICPC-2)". Available from: http://goo.gl/d97aO, 2013.

[110] American Medical Association. "Current procedural terminology". Available from: http://goo.gl/ctCN0, n.d.

[111] H. Park and N. Hardiker. "Clinical terminologies: a solution for semantic interoperability". Journal of Korean Society of Medical Informatics, vol. 15, no. 1, pp. 1-11, 2009.

[112] ISO. "ISO 21090:2011 - Harmonized Data Types for Information Interchange". Available from: http://goo.gl/12xZ6, 2011.

[113] National Department of Health. "EHealth strategy South Africa 2012-2016", 2012.

[114] R. Foster. "Review of Developing Country Health Information Systems: A High Level Review to Identify Health Enterprise Architecture Assets in Ten African Countries". Available from: http://goo.gl/v1X8A2, 2012.

[115] H. S. Fraser, P. Biondich, D. Moodley, S. Choi, B. W. Mamlin and P. Szolovits. "Implementing electronic medical record systems in developing countries". Informatics in primary care, vol. 13, no. 2, pp. 83-96, 2005.

[116] T. Simbini, R. Foster, P. Nesara and L. C. C. Hullin. "Monitoring diseases across borders: African regional integrative information systems." Studies in health technology and informatics, vol. 160, no. Pt 1, p. 401, 2010. 
[117] Kenyan Ministry of Health. "Standards and Guidelines for Primary Health Care Electronic Medical Record Systems in Kenya", 2013.

[118] R. Crichton, D. Moodley, A. Pillay and C. J. Seebregts. "An interoperability architecture for the health information exchange in Rwanda". 2012.

[119] ISO. "ISO Members". Available from: http:/goo.gl/vCSRE, n.d.

[120] ISO. "TC 215 Health Informatics". Available from: http://goo.gl/BxsbE, n.d.

[121] ITU. "Measuring and reducing the standards gap". Available from: http://goo.gl/VTjdo, 2009.

[122] The Rockefeller Foundation. "From silos to systems: An overview of eHealth's Transformative Power". Available from: http://goo.gl/cmqoj, 2010.

[123] International Federation of Standards Users. "Guidelines to Assist Members of Standards Committees in Preparing User-Oriented European Standards". Available from: http://goo.gl/cU0pz, 2008.

[124] European Commission. "EU eHealth Interoperability Roadmap". Available from: http://goo.gl/wewKA, 2010 .

[125] Joint Initiative Council. "Joint Initiative on SDO Global Health Informatics Standardisation Charter". Available from: http://goo.gl/9JdXv, 2009.

[126] IHTSDO. "SNOMED CT Licensing". Available from: http://goo.gl/ylVcc, n.d.

[127] Health Level 7. "HL7 Licenses its standards at no cost and future membership model". Available from: http://goo.gl/jVeq6, 2013.

[128] PHTF. "Public Health Task Force: Mission". Available from: http://goo.gl/ZIbRJ, 2013.

[129] Health Level 7. "International Mentoring Committee". Available from: http://goo.gl/zx8bU, 2007.

[130] Integrating the Healthcare Enterprise. "Member organisations". Available from: http://goo.gl/kEdsG, 2012 . 